\title{
Adherence to case management guidelines of Integrated Management of Childhood Illness (IMCI) by healthcare workers in Tshwane, South Africa
}

\author{
M C Mulaudzi, MB ChB, MMed (Paed), Dip HIV Man (SA) \\ Department of Paediatrics and Child Health, Kalafong Hospital, University of Pretoria, South Africa
}

Corresponding author: M C Mulaudzi (mphele.mulaudzi@up.ac.za)

\begin{abstract}
Background. Integrated Management of Childhood Illness (IMCI) is an essential strategy known to deliver childhood interventions that reduce the under-five mortality rate.

Objective. To evaluate the adherence to the IMCI case management guidelines by primary healthcare workers in the Tshwane area, South Africa. Methods. The study was conducted between July and December 2012 on children referred from clinics to Kalafong Hospital. Data on IMCI clinical symptoms and signs, classification and treatment given at the clinics before referral to the hospital were collected from patients referral letters. An interview with the caregiver on counselling received at the clinic was done using an adapted World Health Organization health facility survey tool.

Results. Eighty children between 2 and 60 months referred from 12 local clinics were included in the study. IMCI classification was done in just over half (52.9\%) of 34 children with cough and $73 \%$ of 15 children with diarrhoea. Only $18 \%$ of children with chest indrawing and fast breathing were classified correctly. Prereferral treatment for all children with severe dehydration had been given correctly but not so for children with severe pneumonia and severe malnutrition. None of the children with severe disease had been checked for glucose levels before referral.

Conclusions. The IMCI guidelines had not been adhered to in all children referred to the hospital. Children, particularly those with severe disease, had been incorrectly classified, leading to inadequate prereferral treatment. Healthcare workers had not given the expected treatment at the clinic before referral.
\end{abstract}

S Afr J Child Health 2015;9(3):89-92. DOI:10.7196/SAJCH.7959

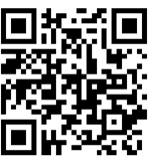

Globally, the Integrated Management of Childhood Illness (IMCI) is a strategy that has been shown to reduce the under-five mortality rate (U5MR) and to assist in the realisation of the Millennium Development Goals (MDGs). ${ }^{[1,2]}$ South Africa (SA) adopted the IMCI strategy in 1996, with the first training of healthcare workers (HCWs) in case management in 1998. By 2001, all provinces had trained some healthcare workers but the coverage varied from province to province ${ }^{[3]}$ Despite SA adopting the IMCI strategy, 47417 children $<5$ years old (35 318 beyond neonatal period) died in 2010 from mainly neonatal conditions, pneumonia, diarrhoea, HIV and malnutrition. Beyond the neonatal period, the latter four conditions contributing to U5MR are included in the IMCI case management guidelines in an attempt to reduce case fatality rates. ${ }^{[4]}$

The IMCI strategy was developed by the World Health Organization (WHO) and the United Nations Children's Fund (UNICEF) in the early 1990s to reduce the U5MR through the integrated management of common childhood diseases, in contrast to vertical programmes that focused on individual disease. The IMCI strategy has three components, namely case management guidelines, health system strengthening and community health messages. The case management guidelines of the IMCI use algorithms of specific symptoms and clinical signs. The patient's condition is classified and recommended treatment administered, including treatment administered at the clinic before hospital referral (prereferral treatment). ${ }^{[5]}$ The major difference from the usual assessments of children is that classification of severity of illness rather than diagnosis is used.
SA research has shown that training in the IMCI case management guidelines improves HCWs' ability to assess, recognise signs of severe illnesses and treat sick children appropriately. ${ }^{[6,7]}$

In order for the IMCI strategy to reduce U5MR, the majority of HCWs, if not all, ought to be trained and need to adhere to the guidelines. Recent data on the numbers and the coverage of IMCItrained HCWs in SA are not available. Chopra et al. ${ }^{[6]}$ have shown that although the guidelines are used, they are not implemented correctly or completely. ${ }^{[5]}$ The Saving Children Report of 2010 2011, by the Child Healthcare Problem Identification Programme (Child PIP), identified failure to follow IMCI assessment and treatment guidelines and failure to recognise the severity of illness as modifiable factors responsible for the death of children in SA, supporting the findings by Chopra et al. ${ }^{[6]}$ that IMCI guidelines are not followed. ${ }^{[8]}$

Research on adherence to the IMCI case management guidelines has been carried out in the primary healthcare (PHC) clinic setting. No research was found to have been carried out in the referral hospital setting to assess adherence to the IMCI guidelines. The motivation to conduct this study in the hospital setting was to reduce the likelihood of the Hawthorne effect, where HCWs in clinics might adhere to guidelines because they are being observed for research purposes. The methodology has some limitations in that it relies on the documented information in the referral letter and the condition of the patient might have changed en route to the hospital.

In view of the high U5MR and the varied coverage of IMCItrained HCWs, the research was conducted at the hospital, with the objective of assessing the adherence to IMCI case management guidelines by HCWs at the clinic level. 


\section{Method}

\section{Study design and setting}

The study was conducted at Kalafong Hospital in Pretoria, SA. This was a cross-sectional study conducted between July and December 2012. Convenience sampling was used. All children referred from PHC clinics to Kalafong Hospital were recruited between $08 \mathrm{~h} 00$ and $16 \mathrm{~h} 00$ on the days when the researcher was available (on average 1 day per week) as there was no funding to employ a full-time person to conduct the research. The PHC clinics that refer to Kalafong Hospital operate on weekdays between $07 \mathrm{~h} 00$ and $16 \mathrm{~h} 00$ and on Saturdays in the morning till 13h00. There is only one clinic that operates 24 hours a day, including weekends and holidays.

\section{Participants and eligibility criteria}

Children aged 2 - 60 months referred from clinics to Kalafong Hospital with medical conditions were recruited. Children referred with surgical and dermatological problems were excluded. On average, 16 - 20 cases are referred daily from PHCs to the paediatrics outpatient department (POPD) over a 5-day working week. The POPD is closed after $16 \mathrm{~h} 00$ and over weekends. It was anticipated that the subjects would be recruited over a period of $8-10$ weeks with the assumption that $\sim 50 \%$ would give consent to be recruited into the study, thus giving a minimum sample size of 80 subjects for analysis.

\section{Measurement and tools used}

Information on IMCI clinical symptoms and signs, classification and prereferral treatment documented in patients' referral letters was collected. Information on counselling received by caregivers regarding the child's condition at the clinic before referral was collected in an interview with the caregiver on arrival at the hospital. A questionnaire adapted from the WHO health facility survey tool to evaluate the quality of care delivered to sick children attending the outpatient facility was used. ${ }^{[9]}$

The IMCI guidelines require that at each consultation of a child aged between 2 and 60 months, HCWs should follow specific steps. Firstly, they should assess for general danger signs, i.e. the inability to drink or breastfeed, the child vomiting everything, convulsions during this illness, and lethargy or unconsciousness. Secondly, the HCW should ask the caregiver about the four main symptoms, i.e. cough or difficulty in breathing, diarrhoea, fever and ear problems. For each symptom present, a list of clinical signs should be checked in the child for the IMCI classification to be done; classifications are categorised according to the severity of the illness. Thirdly, the HCW should consider the following conditions: measles, HIV infection and tuberculosis (TB) if clinical symptoms and signs listed for consideration are found.
Nutritional and immunisation status should also be checked in all children. Treatment is then recommended according to the classification of the condition.

\section{Statistics}

The data were entered into an Excel (Microsoft, USA) spreadsheet, cleaned and then imported into Stata statistical software release 12 (StataCorp, USA) for statistical analysis.

\section{Ethics}

Ethical approval was granted by the Faculty of Health Sciences Research Ethics Committee, University of Pretoria. Informed consent was obtained from parents who agreed to participate in the study.

\section{Results}

A total of 110 children were recruited into the study. Children between 2 and 60 months old who met the inclusion criteria and with written consent to participate in the research were enrolled. During the study period, 699 new patients were referred to the POPD (not only from the PHC clinics). Of the original 110 recruited, 80 children were enrolled - 30 with surgical and dermatological conditions were excluded. A total of 52 of the 80 children were male. Half of the children were $<1$ year old. Children were referred from 12 surrounding clinics in the Tshwane subdistricts 3 and 4 .

\section{Presenting symptoms}

Of the 80 children enrolled, 55 had documented four IMCI symptoms (cough or difficulty breathing, diarrhoea, fever or ear problem), 13 had other symptoms, and 12 had no documented symptoms but were referred for malnutrition, HIV, TB or measles. A total of 76 occurrences of IMCI symptoms in 55 children and 15 occurrences of non-IMCI symptoms were documented in the referral letters. Not all referral letters had symptoms documented. The most common single symptom at presentation was cough, followed by diarrhoea and fever (Table 1). Thirty-four $(42.5 \%)$ patients presented with multiple symptoms. The only general danger sign documented was lethargy in an infant who presented with cough and diarrhoea; this was classified as cough and cold, and severe dehydration. The patient received ceftriaxone and co-trimoxazole before referral to the hospital.

\section{IMCI classification and management} For each of the four IMCI presenting symptoms, the signs and classification documented in the referral letter were identified. Table 2 shows the clinical signs, classifications and urgent prereferral treatment given at the clinic before referral to the hospital.
IMCI classification was done in just over half (52.9\%) of 34 children with cough and $73 \%$ of 15 children with diarrhoea. Only $18 \%$ of children with chest indrawing were classified correctly as severe pneumonia, and half with fast breathing were classified correctly. A total of 5 cases were classified as $\mathrm{TB}$ exposure, 11 as probable $\mathrm{TB}, 2$ as symptomatic HIV, 10 as HIV-exposed and 1 as measles.

Nutritional assessment was only recorded in $24(30 \%)$ children, with 6 as severe malnutrition, 8 as not growing well and 10 as growing well. Four children had anaemia classification. 'Normal weight' was mostly used rather than the IMCI term 'growing well' in the referral letters. Of the six children with severe malnutrition, only one had received vitamin $\mathrm{A}$, three had received antibiotics, and blood glucose levels had not been checked in any of them.

\section{Counselling}

Counselling of $59(73.7 \%)$ caregivers on the condition of the children was done at the clinics before referral of the children to the hospital (Table 3). Caregivers were counselled on the medical condition of the child, immunisations, how to administer treatment and how to recognise symptoms and signs that indicate when the child should return to the health facility.

Table 1. Frequency of the four IMCI symptoms

\begin{tabular}{ll}
\hline Symptom & $\boldsymbol{n}$ \\
\hline Cough or difficulty in breathing (cough) & 34 \\
Cough only & 19 \\
Cough and diarrhoea & 2 \\
Cough and fever & 11 \\
Cough, diarrhoea and fever & 1 \\
Cough and ear problem & 1 \\
Diarrhoea & 15 \\
Diarrhoea only & 9 \\
Diarrhoea and cough & 2 \\
Diarrhoea and fever & 3 \\
Diarrhoea, cough and fever & 1 \\
Fever & 22 \\
Fever only & 6 \\
Fever and cough & 11 \\
Fever and diarrhoea & 3 \\
Fever and ear problem & 2 \\
Ear problems & 5 \\
Ear problem only & 2 \\
Ear problem and fever & 2 \\
Ear problem and cough & 1 \\
&
\end{tabular}


Table 2. IMCI clinical signs, classification and prereferral treatment

\begin{tabular}{|c|c|c|c|c|c|c|}
\hline $\begin{array}{l}\text { Presenting } \\
\text { symptoms } \\
(n)\end{array}$ & $\begin{array}{l}\text { IMCI } \\
\text { signs as } \\
\text { documented } \\
\text { in referral } \\
\text { letter }(n)\end{array}$ & $\begin{array}{l}\text { Total IMCI } \\
\text { classification as } \\
\text { documented in } \\
\text { referral letter } \\
(n)\end{array}$ & $\begin{array}{l}\text { Percentage } \\
\text { of IMCI } \\
\text { classification } \\
\text { done per clinical } \\
\text { signs }\end{array}$ & $\begin{array}{l}\text { Percentage } \\
\text { of IMCI } \\
\text { classification } \\
\text { correctly assigned } \\
\text { per clinical signs }\end{array}$ & $\begin{array}{l}\text { Percentage } \\
\text { of total IMCI } \\
\text { classification } \\
\text { done per } \\
\text { symptoms }\end{array}$ & $\begin{array}{l}\text { Treatment given at clinic } \\
\text { before referral according } \\
\text { to documented } \\
\text { classification (both } \\
\text { correct and incorrect) }\end{array}$ \\
\hline \multirow[t]{5}{*}{$\begin{array}{l}\text { Cough and } \\
\text { difficulty } \\
\text { breathing } \\
(34)\end{array}$} & $\begin{array}{l}\text { Chest } \\
\text { indrawing } \\
\text { (11) }\end{array}$ & $\begin{array}{l}\text { Severe } \\
\text { pneumonia } \\
\text { or very severe } \\
\text { disease (4) }\end{array}$ & $4 / 11=36.4 \%$ & $2 / 11=18.2 \%^{*}$ & $\begin{array}{l}4+6+2+2+4 \\
=18 / 34 \text { cough } \\
\text { symptoms } \\
=52.9 \%\end{array}$ & $\begin{array}{l}3 \text { received ceftriaxone } \\
1 \text { received co-trimoxazole } \\
3 \text { received oxygen } \\
\text { No glucose done }\end{array}$ \\
\hline & $\begin{array}{l}\text { Fast } \\
\text { breathing } \\
(14)\end{array}$ & Pneumonia (6) & $\begin{array}{l}6+2+2 \\
=10 / 14 \\
=71.5 \%\end{array}$ & $\begin{array}{l}4+1+2 \\
=7 / 14 \\
=50 \%\end{array}$ & - & $\begin{array}{l}3 \text { received amoxicillin } \\
1 \text { received co-trimoxazole } \\
3 \text { received inhalation }\end{array}$ \\
\hline & & $\begin{array}{l}\text { Wheeze, first } \\
\text { episode ( } 2)\end{array}$ & - & - & - & - \\
\hline & & $\begin{array}{l}\text { Recurrent wheeze } \\
\text { (2) }\end{array}$ & - & - & - & - \\
\hline & $\begin{array}{l}\text { No fast } \\
\text { breathing (4) }\end{array}$ & $\begin{array}{l}\text { Cough and cold } \\
\text { (4) }\end{array}$ & $4 / 4=100 \%$ & $3 / 4=75 \%$ & - & - \\
\hline \multirow[t]{3}{*}{$\begin{array}{l}\text { Diarrhoea } \\
\text { (15) }\end{array}$} & Lethargy (2) & $\begin{array}{l}\text { Severe } \\
\text { dehydration (3) }\end{array}$ & $\begin{array}{l}\text { Other signs } \\
\text { required to come } \\
\text { to classification } \\
\text { were not recorded }\end{array}$ & $\begin{array}{l}3+7+1 \\
=11 / 15 \text { diarrhoea } \\
\text { symptoms } \\
=73 \%\end{array}$ & $\begin{array}{l}\text { All received IVI } \\
\text { fluid }\end{array}$ & - \\
\hline & $\begin{array}{l}\text { Sunken eyes } \\
(7)\end{array}$ & $\begin{array}{l}\text { Some dehydration } \\
\text { (7) }\end{array}$ & - & - & $\begin{array}{l}\text { No documentation } \\
\text { of ORS }\end{array}$ & - \\
\hline & $\begin{array}{l}\text { Absent (3) } \\
\text { (drinking well, } \\
\text { no sunken } \\
\text { eyes, no } \\
\text { lethargy) }\end{array}$ & $\begin{array}{l}\text { No visible } \\
\text { dehydration (1) }\end{array}$ & $1 / 3=33 \%$ & - & - & - \\
\hline \multirow[t]{2}{*}{ Fever (22) } & $\begin{array}{l}\text { Stiff neck } \\
\text { or bulging } \\
\text { fontanel ( } 2 \text { ) }\end{array}$ & $\begin{array}{l}\text { Suspected } \\
\text { meningitis (1) }\end{array}$ & $\begin{array}{l}\text { Fever alone only } \\
\text { occurred in } \\
6 \text { instances }\end{array}$ & $\begin{array}{l}2 / 6 \text { fever alone } \\
\text { symptoms } \\
=33.3 \%\end{array}$ & $\begin{array}{l}1 \text { received } \\
\text { ceftriaxone }\end{array}$ & - \\
\hline & $\begin{array}{l}\text { Absent (no } \\
\text { stiff neck } \\
\text { or bulging } \\
\text { fontanel) (1) }\end{array}$ & $\begin{array}{l}\text { Suspected severe } \\
\text { malaria (1) }\end{array}$ & - & - & $\begin{array}{l}10 / 22(45.4 \%) \\
\text { received } \\
\text { paracetamol }\end{array}$ & - \\
\hline \multirow[t]{3}{*}{$\begin{array}{l}\text { Ear } \\
\text { problems } \\
(5)\end{array}$} & Ear pain (1) & $\begin{array}{l}\text { Acute ear } \\
\text { infection (1) }\end{array}$ & $1 / 1=100 \%$ & $1 / 1=100 \%$ & $\begin{array}{l}1 / 5 \text { ear problem } \\
\text { symptoms } \\
=20 \%\end{array}$ & $\begin{array}{l}\text { Only } 1 \text { patient with ear pain } \\
\text { and severe malnutrition } \\
\text { received ceftriaxone }\end{array}$ \\
\hline & $\begin{array}{l}\text { Pus draining } \\
\text { for }<14 \text { days } \\
\text { (1) }\end{array}$ & - & - & - & - & - \\
\hline & $\begin{array}{l}\text { No swelling } \\
\text { behind the } \\
\text { ear (1) }\end{array}$ & - & - & - & - & - \\
\hline
\end{tabular}

\section{Discussion}

The results of the study suggest that the IMCI case management guidelines are not adhered to in the assessment and management of children by clinic HCWs before referral to Kalafong Hospital. The classification of the conditions was incomplete and incorrect in some cases, as only $18 \%$ of children presenting with cough and chest indrawing were correctly classified as severe pneumonia. The recommended prereferral treatment at the clinic was not always administered.

Forty-two per cent of children presented with multiple symptoms. This high percentage indicates the value of the integrated guidelines as opposed to single disease-focus guidelines. The high percentage of multiple symptoms also suggests the appropriateness of the referrals. However, some symptoms were not addressed by the IMCI case management guidelines.

IMCI classifications were not done for all the presenting symptoms in children presenting with multiple symptoms; this finding concurs with that in a study done by Walter et al ${ }^{[10]}$ in Tanzania. In the studies done by Chopra et al. ${ }^{[6]}$ in Cape Town and Horwood et al. ${ }^{[7]}$ in KwaZulu-Natal and Limpopo, incorrect classification was found mainly for the symptoms cough and diarrhoea, and for the sign very low weight; the same applied in this study. 
Table 3. Counselling received by caregivers at the clinic before referral of children to the hospital

\begin{tabular}{|c|c|c|c|}
\hline Topic & $\begin{array}{l}\text { Counselling } \\
\text { done, } \\
n(\%)\end{array}$ & $\begin{array}{l}\text { Counselling } \\
\text { not done, } \\
n(\%)\end{array}$ & $\begin{array}{l}\text { Counselling } \\
\text { information } \\
\text { missing, } n(\%)\end{array}$ \\
\hline Immunisation & $59(73.7)$ & $2(2.5)$ & $19(23.7)$ \\
\hline $\begin{array}{l}\text { Medical } \\
\text { condition }\end{array}$ & $61(76.2)$ & $18(22.5)$ & $1(1.2)$ \\
\hline $\begin{array}{l}\text { Administration } \\
\text { of treatment }\end{array}$ & $47(58.7)$ & $27(33.7)$ & $6(7.5)$ \\
\hline $\begin{array}{l}\text { Oral hydration } \\
\text { solution } \\
\text { reconstitution }\end{array}$ & $20(25.0)$ & $26(32.5)$ & $34(42.5)$ \\
\hline \multicolumn{4}{|l|}{ Danger signs } \\
\hline Fever & $14(17.5)$ & $52(65.0)$ & $14(17.5)$ \\
\hline Fast breathing & $19(23.7)$ & $45(56.2)$ & $16(20.0)$ \\
\hline $\begin{array}{l}\text { Blood in the } \\
\text { stool }\end{array}$ & $7(8.7)$ & $38(47.5)$ & $35(43.7)$ \\
\hline $\begin{array}{l}\text { Difficulty } \\
\text { breathing }\end{array}$ & $16(20.0)$ & $49(61.2)$ & $15(18.7)$ \\
\hline $\begin{array}{l}\text { Not able to } \\
\text { drink or feed }\end{array}$ & $33(41.2)$ & $38(47.5)$ & $9(11.2)$ \\
\hline Convulsions & $8(10.0)$ & $41(51.5)$ & $31(61.2)$ \\
\hline $\begin{array}{l}\text { Child becoming } \\
\text { sicker }\end{array}$ & $48(60.0)$ & $32(40.0)$ & 0 \\
\hline
\end{tabular}

Incorrect classification resulted in severe classifications being classified as less severe categories in our study, a finding which concurs with those of Horwood et al. ${ }^{[7]}$ and Walter et al. ${ }^{[10]}$ Certain individual clinical signs, such as chest indrawing and very low weight, categorise the condition as severe without the need for another sign; as such these signs should have the same importance as general danger signs to prevent afflicted children from being sent home and to facilitate their immediate attention in health facilities.

Prereferral treatment was done well for children with severe dehydration, which is an improvement from the previously stated studies. ${ }^{[6,7]}$ However, fewer children with severe pneumonia received ceftriaxone, co-trimoxazole and oxygen before referral, which are considered essential interventions to reduce death due to pneumonia. ${ }^{[11]}$ None of the children with severe malnutrition received vitamin A, similar to the 9\% reported by Chopra et al ${ }^{[6]}$ The importance of vitamin A appears not to be realised by HCWs, as the administration of vitamin A to children is still very low, more than 10 years on from its recommended implementation in IMCI. Blood glucose was also not checked in all children with severe pneumonia and severe malnutrition, resulting in failure to recognise hypoglycaemia, a cause of death in children with severe acute malnutrition.

Besides incorrect and incomplete classifications, very few children had nutritional and HIV status assessed, and treatment was not given according to guidelines. Assessment for severe malnutrition and HIV is important as these children may require additional care before transfer to hospital, which may improve survival.

Pneumonia, diarrhoea and malnutrition are leading causes of death for $<5$-year-olds. ${ }^{[4,11,12]}$ To reduce the U5MR, the IMCI case management of these conditions ought to be adhered to before hospital referral.

It was encouraging to learn that two-thirds of caregivers were counselled on the medical condition of the child, on the importance of immunisations and on the need to return to the clinic if the child got sicker. Counselling on the clinical signs to be used to determine when to return to the health facility was low, possibly because the patients were being referred to the next level of care rather than going home.

\section{Study limitations}

It is not known whether the primary HCWs who saw the children were IMCI trained. Another limitation is that not everything done to the patient at the clinic had been documented in the referral letter. Prereferral treatment given at the clinic but not documented in the referral letter may result in a child receiving high or excessive doses of medication, which might have side-effects. Children managed at the clinic level by healthcare workers not IMCI trained means that the high coverage of IMCI interventions required to have child survival benefits is not reached.

\section{Conclusion}

IMCI guidelines were not always adhered to and IMCI classifications for children referred from clinics to the hospital were often incorrect and incomplete. Children with chest indrawing and fast breathing were classified incorrectly, resulting in inappropriate treatment being received before referral to hospital. Nutritional status was documented in only one-quarter of children referred. None of the children with severe pneumonia and severe malnutrition had glucose levels checked before referral.

We recommend that the HCWs in PHC clinics be trained and supported to use the IMCI guidelines. Messages to HCWs about the chest indrawing sign should have the same importance as the IMCI general danger signs, even though the WHO no longer recommends this sign as needing referral. We also recommend that appropriate IMCI referral forms or equivalent should be used to assist in adequately documenting information and treatment done at the clinic before referral.

Acknowledgements. Dr Campos for data collection, Dr Olorungo for statistical input and Prof. Wittenberg for encouragement.

\section{References}

1. Jones G, Steketee R, Black R, et al. Child survival II: How many child deaths can we prevent this year? Lancet 2003;362(9377):65-71. [http://dx.doi.org/10.1016/ S0140-6736(03)13811-1]

2. Chopra M, Mason E, Borrazzo J, et al. Ending of preventable deaths from pneumonia and diarrhoea: An achievable goal. Lancet 2013;381(9876):14991506. [http://dx.doi.org/10.1016/ S0140-6736(13)60319-0]

3. World Health Organization (WHO), United Nations International Children's Fund (UNICEF), Italian Government. Report of IMCI Health Facility Survey Free State, Gauteng and Western Cape. Pretoria: Business print centre, 2003.

4. Statistics South Africa. Mortality and Causes of Death in South Africa, 2010: Findings from Death Notification. Pretoria: Statistics South Africa, 2013.

5. Gove S. Integrated management of childhood illness by outpatient healthcare workers: Technical basis and overview. The WHO working group on guidelines for integrated management of the sick child. Bull World Health Organ 1997;75(Suppl 1):7-24. http://whqlibdoc.who.int/bulletin/1997/supplement/ bulletin_1997_75(supp1)_7-24.pdf (accessed 22 September 2014).

6. Chopra M, Patel S, Cloete K, Sanders D, Peterson S. Effect of an IMCI intervention on quality of care across four districts in Cape Town, South Africa. Arch Dis Child 2005;90(4):397-401. [http://dx.doi.org/10.1136/adc.2004.059147]

7. Horwood C, Vermaak K, Rollins N, Haskins L, Nkosi P, Qazi S. An evaluation of the quality of IMCI assessments among IMCI trained health workers in South Africa. PLoS ONE 2009;4(6):e5937. [http://dx.doi.org/10.1371/journal.pone.0005937]

8. Stephen CR, Bamford LJ, eds. Saving Children 2010 - 2011: A Seventh Survey on Child Healthcare in South Africa. Pretoria: Tshepesa Press, MRC, CDC, 2013.

9. WHO. WHO Health Facility Survey: Tool to Evaluate the Quality of Care Delivered to Sick Children Attending Outpatient Facility. Geneva: WHO, 2003.

10. Walter ND, Lyimo T, Skarbinski J, et al. Why first-level health workers fail to follow guidelines for managing severe disease in children in the Coast Region, the United Republic of Tanzania. Bull World Health Organ 2009;87(2):99-107. [http://dx.doi.org/10.2471/BLT.08.050740]

11. Gill CJ, Young M, Schroder K, et al. Bottlenecks, barriers, and solutions: Results from multicountry consultations focused on reduction of childhood pneumonia and diarrhoea deaths. Lancet 2013;381 (9876):1487-1498. [http:// dx.doi.org/10.1016/S0140-6736(13)60314-1]

12. United Nation International Children's Fund (UNICEF), developed by the UN Inter-agency Group for Child Mortality Estimation. Levels and Trends in Child Mortality, Estimates 2013 Report. New York: UNICEF, 2013. http://www.childinfo. org/files/Child_Mortality_Report_2013.pdf (accessed 22 September 2014) 